layered thickened cortex) was investigated using specific antibodies against the protein product of LIS-1, the gene responsible for MDS phenotype, at the National Center of Neurology and Psychiatry, Kodaira, Tokyo. (Isumi H, Takashima S, Kakita A, et al. Pediatr Neurol Jan 1997;16:42-44). Loss of LIS-1 immunoreactivity occurred in brains with MDS, but not with isolated lissencephaly, holoprosencephaly, Fukuyama-type congenital muscular dystrophy, and Zellweger syndrome. Loss of LIS-1 gene product is specific to the abnormal neuronal migration in Miller-Dieker syndrome.

\title{
UNTREATED TONIC-CLONIC SEIZURE OUTCOME
}

The clinical course of untreated tonic-clonic seizures in 204 children aged 1 month to 16 years was studied at the University Hospital Rotterdam, Netherlands. Follow-up continued until start of drug treatment (78), the fourth untreated seizure (41), or for two years without treatment (85). Forty-two per cent had a decelerating pattern; they were free of seizures despite treatment being withheld. Of 41 with four or more untreated seizures, 8 had an accelerating pattern, the intervals between seizures becoming shorter. In 110 children the disease process could not be classified because treatment was started after the first, second, or third seizure. (Van Donselaar CA, Brouwer OF, Geerts AT, et al. Clinical course of untreated tonic-clonic seizures in childhood: prospective, hospital based study. BMI 8 Feb 1997;314:401-404). (Respond: Dr CA van Donselaar, St Clara Hospital, Olympiaweg 350, 3078 HT Rotterdam, Netherlands).

COMMENT. Previous reports of an accelerating pattern, or decreasing interval between successive untreated seizures, support the concept that seizures beget seizures (Gowers, 1881) and early introduction of antiepileptic drug treatment is recommended. The present study fails to confirm the fear that untreated tonic-clonic seizures will evolve into a progressive disorder, and favors a delay in treatment. An individualized approach is probably most appropriate, each child's treatment based on factors predictive of seizure recurrence. For further reference to treatment onset and epilepsy prognosis, see Progress in Pediatric Neurology II, PNB Publ, 1994:pp92-93.

The risk for psychiatric and psychosomatic disorders is higher than expected in adults with childhood-onset epilepsy, regardless of continued treatment with AEDs, in a study at the University of Turku, Finland. (Jalava M, Sillanpaa M. Concurrent illnesses in adults with childhood-onset epilepsy: a population-based 35-year follow-up study. Epilepsia Dec 1996;37:1155-1163).

\section{BENIGN EPILEPSY WITH C-T SPIKES (BECT) OUTCOME}

A meta-analysis of 13 cohorts, comprising 794 patients, selected according to ILAE and other criteria from 525 publications on BECT, was conducted at Leiden University Hospital, Netherlands. Age at onset ranged from 3 months to 14 years, and age at last seizure ranged from 3 to 18 years. At an older age, the proportion of patients in remission was 0.9997. Despite this apparent excellent prognosis, the outcome of BECT in a child just developing seizures could not be determined satisfactorily from the meta-analysis, because of the retrospective design and unclear selection of patients studied. (Bouma PAD, Bovenkerk AC, Westendorp RGJ, Brouwer OF. The course of benign partial epilepsy of childhood with centrotemporal spikes: a meta-analysis. Neurology Feb 1997;48:430-437). (Reprints: Dr PAD Bouma, Department of Neurology, Leiden University Hospital, PO Box 9600, 2300 RC Leiden, Netherlands).

COMMENT. AED treatment was started in $81.6 \%$ of the patients in the 
above studies. The indications to start treatment were unclear, but included repeated seizures, especially occurring during waking hours. Relapses after AED withdrawal occurred in $14 \%$ of patients.

The functional organization of the interictal spike complex in benign rolandic epilepsy, also called BECT, was studied at the Universitatsklinik fur Neurologie, Donauspital; and Kinderklinik Glanzing, Vienna, Austria. (Baumgartner C, Graf M, Doppelbauer A, et al. Epilepsia Dec 1996;37:1164-1174). The interictal epileptiform spike complex is generated by multiple, simultaneously active neuronal populations within the central region.

\section{ABSENCE EPILEPSY PSYCHOSOCIAL OUTCOME}

The long-term psychosocial outcome in 56 patients aged 18 years or older with typical absence epilepsy and 61 controls with juvenile rheumatoid arthritis (JRA) was studied at the Royal University Hospital, Saskatoon, Saskatchewan, and the Izaak Walton Killam-Grace Health Center, and Dalhousie University Faculty of Medicine, Halifax, Nova Scotia, Canada. Structured interviews were conducted at a mean age of 23 years. More patients with absence epilepsy than with JRA had remission at follow-up (57\% vs $28 \%$ ). Patients with absence epilepsy had greater difficulties in school than those with JRA, and were less likely to graduate from high school. They also had a higher incidence of behavioral problems, a higher rate of unplanned pregnancy among women, they were more likely to drink alcohol to excess, have poor relationships with siblings, few friends, worked for fewer months in a year, more often in unskilled jobs, and more frequently dissatisfied with their employment. Patients with uncontrolled seizures had the poorest psychosocial outcome. (Wirrell EC, Camfield CS, Camfield PR et al. Long-term psychosocial outcome in typical absence epilepsy. Sometimes a wolf in sheeps' clothing. Arch Pediatr Adolesc Med Feb 1997;151:152-158). (Respond: Dr Carol S Camfield, Department of Pediatrics, Izaak Walton Killam-Grace Health Center, 5850 University Ave, Halifax, Nova Scotia, Canada B3J 3G9).

COMMENT. Chronic illness in childhood has an adverse effect on psychosocial behavior, absence epilepsy having a worse outcome than juvenile rheumatoid arthritis. Patients with uncontrolled seizures have the poorest prognosis, but factors related to treatment and control of seizures such as AED side-effects do not affect the outcome. Categories of adverse psychosocial outcome include academic-personal, behavioral, employmentfinancial, family relations, and social-personal relations. The journal editor, Catherine D DeAngelis comments:"Apparently much more than medications needs to be monitored and adjusted" in the management of children with absence epilepsy. In my practice, a factor which concerns adolescents with epilepsy above all others is the permit to drive an automobile. This question has far reaching psychosocial implications for young people and needs to be addressed fully with the patient and parents.

Juvenile diabetes is usually compared to absence epilepsy, when explaining the hardships of treatment and prognosis to a newly diagnosed young patient. I am wondering how these diseases would have contrasted in terms of psychosocial outcome, since both have no outward evidence of physical incapacity, unlike JRA, both require daily medication, and both are long-term chronic illnesses. 